\title{
Cities may save some threatened species but not their ecological functions
}

\author{
Álvaro Luna ${ }^{\text {Corresp., }}{ }^{1}$, Pedro Romero Vidal ${ }^{1}{ }^{\text {, Fernando Hiraldo }}{ }^{1}$, Jose L. Tella ${ }^{\text {Corresp. }}{ }^{1}$ \\ ${ }^{1}$ Department of Conservation Biology, Estación Biológica de Doñana, CSIC, Sevilla, Spain \\ Corresponding Authors: Álvaro Luna, Jose L. Tella \\ Email address: alvalufer@gmail.com, tella@ebd.csic.es
}

Background. Urbanization is one of the main causes of biodiversity loss worldwide. Wildlife responses to urbanization, however, are greatly variable and, paradoxically, some threatened species may achieve much larger populations in urban than in natural habitats. Urban conservation hotspots may therefore help some species avoid regional or even global extinctions, but not conserve their often overlooked ecological functions in the wild. We aim to draw attention to this issue using two species of globally threatened parrots occurring in the Dominican Republic: the Hispaniolan amazon (Amazona ventralis) and the Hispaniolan parakeet (Psittacara chloropterus).

Methods. We conducted a large-scale roadside survey in June 2017 across the country to estimate the relative abundance of parrots in natural habitats, rural habitats, and cities. We combined this with informal interviews with local people, to collect information on past and current human impacts on parrot populations. We also looked for foraging parrots to assess their potential role as seed dispersers, an ecological function that has been overlooked until very recently.

Results. Relative abundances of both parrot species were negligible in rural areas and very low in natural habitats. They were generally between one and two orders of magnitude lower than that of congeneric species inhabiting other Neotropical ecosystems. Relative abundances were six times higher in cities than in natural habitats in the case of the Hispaniolan parakeet and three times higher in the case of the Hispaniolan amazon. People indicated hunting for a source food and to mitigate crop damage as causes of parrot population declines, and a vigorous illegal trade for parrots (131 individuals recorded, $75 \%$ of them poached very recently), mostly obtained from protected areas where the last small wild populations remain. We observed parrots foraging on 19 plant species from 11 families, dispersing the fruits of 14 species by carrying them in their beaks and consuming them in distant perching trees. They discarded undamaged mature seeds, with the potential to germinate, in $99.5 \%$ of cases $(n=306)$, and minimum dispersal distances ranged from 8 to $155 \mathrm{~m}$ (median=37 m).

Discussion. The loss of ecological functions provided by some species when they disappear from natural habitats and only persist in cities may have long-term, unexpected effects on ecosystems. Our example demonstrates how two cities may soon be the last refuges for two endemic parrots if overharvesting continues, in which case their overlooked role as seed dispersers would be completely lost in nature. The functional extinction of these species could strongly affect vegetation communities in an island environment where seed-dispersal species are naturally scarce. While conservation plans must include urban populations of threatened species, greater efforts are needed to restore their populations in natural habitats to conserve ecological functions. 
1 Cities may save some threatened species but not their ecological functions

2

3 Álvaro Luna*, Pedro Romero-Vidal, Fernando Hiraldo, José L. Tella

4

5 Department of Conservation Biology, Estación Biológica de Doñana (CSIC), Avda. Américo

6 Vespucio s/n, 41092 Sevilla, Spain.

7 Corresponding author*: Álvaro Luna

8 e-mail: aluna@ebd.csic.es

9

10

11

12

13

14

15

16

17

18

19

20

21

22

23

24 


\section{Abstract}

Background. Urbanization is one of the main causes of biodiversity loss worldwide. Wildlife responses to urbanization, however, are greatly variable and, paradoxically, some threatened species may achieve much larger populations in urban than in natural habitats. Urban conservation hotspots may therefore help some species avoid regional or even global extinctions, but not conserve their often overlooked ecological functions in the wild. We aim to draw attention to this issue using two species of globally threatened parrots occurring in the Dominican Republic: the Hispaniolan amazon (Amazona ventralis) and the Hispaniolan parakeet (Psittacara chloropterus).

Methods. We conducted a large-scale roadside survey in June 2017 across the country to estimate the relative abundance of parrots in natural habitats, rural habitats, and cities. We combined this with informal interviews with local people, to collect information on past and current human impacts on parrot populations. We also looked for foraging parrots to assess their potential role as seed dispersers, an ecological function that has been overlooked until very recently.

Results. Relative abundances of both parrot species were negligible in rural areas and very low in natural habitats. They were generally between one and two orders of magnitude lower than that of congeneric species inhabiting other Neotropical ecosystems. Relative abundances were six times higher in cities than in natural habitats in the case of the Hispaniolan parakeet and three times higher in the case of the Hispaniolan amazon. People indicated hunting for a source food and to mitigate crop damage as causes of parrot population declines, and a vigorous illegal trade for parrots (131 individuals recorded, $75 \%$ of them poached very recently), mostly obtained from protected areas where the last small wild populations remain. We observed parrots foraging on 19 plant species from 11 families, dispersing the fruits of 14 species by carrying them in their beaks and consuming them in distant perching trees. They discarded undamaged mature seeds, with the potential to germinate, in $99.5 \%$ of cases $(n=306)$, and minimum dispersal distances ranged from 8 to $155 \mathrm{~m}$ (median=37 m). 
54 Discussion. The loss of ecological functions provided by some species when they disappear from natural habitats and only persist in cities may have long-term, unexpected effects on ecosystems. Our example demonstrates how two cities may soon be the last refuges for two endemic parrots if overharvesting continues, in which case their overlooked role as seed dispersers would be completely lost in nature. The functional extinction of these species could strongly affect vegetation communities in an island environment where seed-dispersal species are naturally scarce. While conservation plans must include urban populations of threatened species, greater efforts are needed to restore their populations in natural habitats to conserve ecological functions.

\section{Introduction}

Urbanization is one of the most rapidly growing, prevalent and lasting causes of habitat change (Seto et al. 2012) and is resulting in the loss of biodiversity through local extinction processes worldwide (McKinney, 2006; Grimm et al. 2008; Sol et al., 2014). However, wildlife responses to urbanization are highly variable: while most species are unable to occupy these new habitats, including endemic and threatened species (González-Oreja 2010), others are able to persist or colonize even the most populated cities (Chace \& Walsh, 2006; Kark et al., 2007; Carrete \& Tella 2011; Sol et al., 2014). Paradoxically, some species achieve much higher densities in urban than in natural habitats and thus, cities arise as conservation hotspots (Mason 2010; Rebolo-Ifrán et al. 2017). Cities have also been known to host some threatened species, thus becoming key refuges to guarantee their persistence. As recent examples, $22 \%$ of the known occurrences of threatened plants in the USA fall within the 40 largest cities (Schwartz et al. 2002), a third of 54 cities sampled by Aronson et al. (2014) contained globally threatened birds, and Australian cities support more threatened plant and animal species than all other non-urban areas on a unit-area basis (Ives et al. 2015). Thus, the conservation of some threatened species is an additional motivation to make urban environments compatible with the persistence of wildlife (Miller \& Hobbs, 2002; Dearborn \& Kark, 2010).

From a species-based conservation point of view, the fact that cities may help some species avoid regional or even global extinctions (Ives et al. 2016; Gibson \& Yong 2017) is a welcomed insight for conservationists and policymakers. However, little attention has been paid to the ecological consequences of the restriction of species to urban environments as their final refuges. Particularly, the loss of ecological functions and ecosystem services provided by species 
84 when they disappear from natural habitats to only persist in urban environments may have longterm, unexpected effects on ecosystems. We aim to draw attention to this likely phenomenon using two species of threatened parrots as an example.

Parrots (Psittaciformes) are among the most threatened bird orders with $28 \%$ of the c. 400 species of the world classified as threatened by the IUCN Red List (Olah et al., 2016). Habitat loss, through logging and the spread of agriculture, is one of the main threats to parrots worldwide (Olah et al. 2016). However, some parrot traits (such as their high inter-individual variability in behavior associated with their relatively large brain sizes, Carrete \& Tella 2011) allow them to successfully colonize and thrive in urban habitats, where they make use of the new food and nesting resources provided by cities (e.g., Fitzsimons et al. 2003; Davies et al. 2011; Tella et al. 2014). On the other hand, parrots are highly valued as pets given their attractive coloration and ability to imitate human speech. This societal demand drives an intense domestic and international trade that contributes to the rarity in the wild of many parrot species (Tella \& Hiraldo 2014, Annorbah et al. 2016, Berkunsky et al. 2017), but also to the establishment of urban parrot populations both within their native and foreign distribution ranges due to the escape or deliberated release of caged parrots (Abellán et al. 2017; Cardador et al. 2017, Mori et al. 2017). This has created a dilemma: while many wild parrot populations are vanishing due to habitat loss and harvesting for the pet trade, some exotic urban populations are flourishing worldwide to the point that their conservation value could overcome concerns about their potential negative impacts as invasive species (Gibson \& Yong 2017). Conservation efforts focused on some urban parrot populations may save those species from extinction (Gigson \& Yong 2017), but not their ecological functions in their native ecosystems, which remain poorly understood. Parrots have been traditionally considered as pure plant antagonists, as they consume fruits, seeds, flowers and other non-reproductive tissues of their food plants. Recent works, however, have suggested that several parrot species also act as plant mutualists through pollination, seed dispersal, and plant healing (Blanco et al. 2018). While the role of parrots as seed dispersers has been largely overlooked (Tella et al. 2015, Blanco et al. 2016), long-distance seed dispersal by parrots has been shown to be key in some ecosystems (Blanco et al. 2015; Tella et al. 2016a, 2016b; Baños-Villalba et al. 2017). Parrots may even shape vegetal landscapes by influencing the spatial distribution and demography of their food plants and vegetal communities (Blanco et al. 2015, Baños-Villalba et al. 2017, Speziale et al. 2018), and plant-parrot mutualistic 
115 interactions may lead to an increase in the robustness of parrot communities when facing the loss

116 of plant species (Montesinos-Navarro et al. 2017). All of these ecological functions may be lost

117 when human persecution causes the disappearance of parrots in the wild, with remaining

118 population confined to urban refuges.

119

120

121

122

123

124

125

126

127

128

129

130

131

132

133

134

135

136

137

138

139

140

141

142

143

Here, we used as a model the two threatened Caribbean parrot species endemic to Hispaniola Island: the Hispaniolan parakeet (Psittacara chloropterus) and the Hispaniolan amazon (Amazona ventralis) (Figure 1). These species are listed by the IUCN Red List as Vulnerable due to their population declines associated with habitat loss, hunting and poaching for the pet trade (BirdLife International, 2016a, 2016b). In fact, these species are known to be trapped and hunted since the Spanish colonization of the island (Wiley \& Kirwan 2013). We therefore hypothesized that 1) past and current human persecution of parrots may cause a contraction of wild populations to predator-free (considering humans as predators through hunting and trapping for the pet trade) urban refuges (Rebolo-Ifrán et al. 2017), and 2) that these parrot species may act as legitimate seed dispersers of several plant species (Blanco et al. 2018), an ecological function thus far overlooked that might be definitively lost if these species continue to disappear in the wild. For testing these hypotheses, we conducted a large-scale field survey to estimate parrot abundances in natural, rural and urban habitats, obtained information from local people to know whether hunting and trapping are still threating these species, and assessed their potential role as seed dispersers.

\section{Material and methods}

\section{Study area and species}

The Dominican Republic is located in the central area of the Caribbean Sea, covering two thirds of La Hispaniola Island (the rest corresponding to Haiti). Since Spanish colonization in 1492, the island habitats have transformed to farmland, with agriculture currently covering $48.7 \%$ of its surface area (World Bank, 2014), although habitat degradation was higher in past decades and centuries (Olivo, 2007). Despite the habitat loss and fragmentation, this country still holds the largest variety of ecosystems in the Caribbean region, due to its mountainous relief (altitude ranging from 0 to 3,098 m.a.s.1.), climate variability, and a large surface area $\left(25,472 \mathrm{~km}^{2}\right)$ 
144 covered by 119 protected areas (c. $50 \%$ of the country). The main ecosystems can be broadly

145 grouped as tropical rainforests in the northern lowlands, coniferous forests in the central 146 mountains, and tropical dry forests in the southern lowlands. By $2001,65 \%$ of the population

147 (8.7 million people) lived in urban areas, with the capital (Santo Domingo) holding 3.5 million

148 people and an urban population growth rate that reached 2.3\% between 2000 and 2005

149 (http://www.nationsencyclopedia.com/Americas/Dominican-Republic-POPULATION.html).

150 The Dominican Republic constitutes the core area for the two endemic Hispaniolan parrot

151 species (P. chloropterus and A. ventralis), which are considered near extinction in Haiti

152 (BirdLife International, 2016a, 2016b). A third, Near Threatened species endemic to Jamaica, the

153 Jamaican parakeet (Eupsittula nana) (BirdLife International, 2016c), has been reported in the

154 Dominican Republic, but its status as a native or alternatively human-mediated introduced

155 species remains uncertain (Latta et al. 2006).

156

157

158

159

160

161

162

163

164

165

166

167

168

169

170

171

172

173

Estimating habitat-related parrot abundances

Habitat use by parrots was assessed through large-scale roadside surveys, conducted under permits from the Ministry of the Environment of the Dominican Republic. Among different methods available to estimate parrot abundance, roadside surveys are recommended given that they allow to sample large areas and thus increase the likelihood of recording parrots, as they usually show low densities and aggregated distributions resulting from their highly-mobile and flocking behavior (Dénes et al. 2018). This methodology has previously allowed the assessment of parrot abundances (Grilli et al. 2012; Blanco et al., 2015; Tella et al. 2016a; Baños-Villalba et al., 2017), of their foraging behavior (Tella et al. 2016b, Montesinos-Navarro et al. 2017), and of the effects of habitat loss and fragmentation in a variety of raptor and parrot species in different Neotropical biomes (Carrete et al., 2009; Tella et al., 2013). One of the authors (AL) travelled throughout the country in June 2016, gathering information on the distribution of habitats across the island. Thereafter, using recent satellite maps, we selected a network of secondary, mostly unpaved roads to be surveyed, which covered natural habitats as well as agricultural land and urbanized areas throughout the country. We included roads that crossed 12 protected areas (including the National Parks del Este, Jaragua, Bahoruco, Sierra de Neiva and Cordillera Central), where natural ecosystems of the island are still well preserved. The road network was plotted on paper maps and uploaded on a portable GPS. We conducted the field survey from 
174 June 6 to June 21, 2017, at the end of the parrots' breeding season (Latta et al. 2006), with $1752,143.5 \mathrm{~km}$ surveyed (Figure 2). Surveys were conducted in the morning and afternoon by 3-4 176 persons driving a car at low speed $(10-25 \mathrm{~km} / \mathrm{h})$. Habitats crossed through the roadside transects 177 were grouped into the main island habitats: 1) coniferous forests, 2) tropical rainforests, 3) 178 tropical dry forests, 4) farmland, 5) small villages, and 6) large cities. We recorded every time 179 the habitat changed from one type to another to measure the length (in $\mathrm{km}$ ) of the habitat crossed 180 by the transect (sub-transect). For each sub-transect we also recorded the number of observed 181 parrots of each species. We briefly stopped the car every time parrots were detected to record the 182 species, number of individuals, their activity, the distance at which they were detected (detection distance) using a laser rangefinder (Leica Geovid 10x42, range: 10-1,300 m), and to georeference the site. All roadside transects were surveyed only once.

The estimation of parrot densities through distance sampling modelling (Blanco et al., 2015; Baños-Villalba et al., 2017) was not possible due to the scarcity of the species and thus the very low number of contacts we obtained for both species of parrots in most habitats (see Results), then precluding obtaining reliable habitat-specific detectability functions (see Dénes et al. 20187 for distance sampling modelling requirements). The number of contacts and associated detection distances of parrots were also low for distance sampling modeling when pooling habitats into three main categories: 1) large cities, 2) rural habitats (grouping villages and farmland, i.e., a mosaic of small villages and houses embedded in agricultural lands), and 3) natural habitats (grouping coniferous, tropical rainforest and tropical dry forests). We thus relied on an index of relative abundance of each species in each habitat as the number of individuals recorded / number of km surveyed (Tella et al. 2013, 2016b, Blanco et al. 2015). Nonetheless, results obtained through this index were highly correlated with those obtained through distance sampling modelling in other parrot communities (Dénes et al., 2018). Differences in relative abundances of each parrot species among large cities, rural and natural habitats were tested using generalized linear models (GLM, Poisson error distribution and log link function), with the number of individuals recorded in each sub-transect as the response variable, the length (in $\mathrm{km}$ ) of each sub-transect as a covariate, and habitat as a fixed factor (Tella et al. 2013). The obtained results could be biased due to potential biases in distances of detection, which ranged between 0 and 1,200 $\mathrm{m}(\mathrm{n}=76)$. Parrots seemed to do not avoid the proximity of the roads surveyed. In fact, $15 \%$ of the observations were recorded just in the border of the roads (distances close to 0 
$205 \mathrm{~m})$, and $35 \%$ of the observations were recorded at distances $\leq 10 \mathrm{~m}$ from the roads. On the other

206 hand, a GLM (with log-transformed detection distances as response variable, normal distribution

207 and identity function) showed no differences between species (Wald $x^{2}=0.91, \mathrm{df}=1, \mathrm{p}=0.327$ )

208 nor an effect of flock size (Wald $x^{2}=1.48, \mathrm{df}=1, \mathrm{p}=0.233$ ), with a marginally significant

209 effect of habitat (Wald $x^{2}=5.11, \mathrm{df}=2, \mathrm{p}=0.078$ ). This effect resulted from a slightly higher

210 detectability of parrots in rural (median detection distance $=68.5 \mathrm{~m}$, range $=5-132 \mathrm{~m}$ ) and

211 natural habitats $($ median $=80.0 \mathrm{~m}$, range $=15-1200 \mathrm{~m})$ than in large cities $($ median $=66.0$,

212 range $=0-350 \mathrm{~m}$ ). From our experience, the highly intense and noisy car traffic and presence of

213 tall buildings made difficult both the oral and visual detection of parrots in cities at larger

214 distances. If anything, this slight bias in detectability would underestimate the relative abundance

215 of parrots in cities compared to natural habitats, thus making our results conservative.

In addition to the above systematic survey, we also looked for flocks of parrots flying at sunset to potential communal roosts. When we located a communal roost, 3-5 people were situated at vantage points to count the number of individuals gathering at the roost site until night time. This information on roost sizes could help future long-term monitoring programs of these species (Dénes et al. 2018).

221

222

223

224

225

226

227

228

229

230

231

232

233

234

\section{Recording conservation threats}

We wanted to know whether the main conservation threats highlighted in the literature, namely poaching for the pet trade and hunting (Latta et al. 2006; BirdLife International 2016a, 2016b), still affect parrot populations in the Dominican Republic. We discarded the possibility of conducting a systematic survey using questionnaires (see methodological recommendations by Young et al. 2018), given that most people could be reluctant to respond as hunting, trapping and trading parrots are illegal activities in Dominican Republic since 2000. Therefore, to answer our simple question (i.e., whether these threats are still alive in the country despite of prohibitions), we simply stopped in different villages while travelling across the country to informally converse with local people we found in the streets. We presented ourselves as foreign ornithologists interested in the observation and conservation of birds and especially of parrots, and thus people viewed us as birdwatching tourists that could not constitute a threat for their potential illegal activities. During these informal talks, we asked people about the current or past presence of parrots in the surroundings and their conservation problems. The fact that we speak the same 
235 language (Spanish) surely facilitated the long and friendly conversations we had, thus gaining 236 confidence on the information obtained (Young et al. 2018). Most people freely responded, 237 providing their perception of past and current status of parrot populations and their threats, and 238 often guided us to the homes of neighbors, family or friends who kept parrots as pets. In such cases, we were allowed by owners to take pictures of their pets and often received voluntary much more information than we expected, including the age of pets, where and how they were obtained, and how much they paid for them. In some cases people also provided details on other threats such as hunting as a food source or to avoid crop damage. We did not record the names of informants, so their identities remain anonymous.

Recording seed dispersal

During and outside of the roadside surveys, we looked for foraging parrots to record seed dispersal through stomatochory, i.e. when parrots fly from a fruiting plant carrying fruits with the beak to handle and consume them in a distant perching tree, then measuring dispersal distances with a laser rangefinder (Tella et al. 2015, 2016a, 2016b; Blanco et al. 2015; Baños-Villalba et al. 2017). We also looked below the identified perching trees for dispersed fruits and seeds that parrots dropped after consumption, and thus estimated a minimum dispersal distance for each seed as the distance to the nearest fruiting plant of the same species (see Tella et al. 2016b). All perching trees were species different to the plant species that produced the dispersed fruits, so there is not the possibility of making mistakes by recording seeds naturally falling to the ground or handled by parrots in the mother tree. We examined every dispersed fruit or seed to determine the proportion of mature, intact seeds (parrots often consumed the fruit pulp and discarded entire seeds) that had the potential to germinate after dispersal by parrots.

\section{Results}

\section{Habitat-related parrot abundances}

Despite our large-scale roadside survey, covering $2,143.5 \mathrm{~km}$, we only obtained 58 records of Hispaniolan parakeets and 18 records of Hispaniolan amazons throughout the country (Figure 2), totaling 438 and 71 individuals, respectively (Table 1). Most of the individuals were recorded in 
263 cities, where the largest relative abundances were obtained (Table 1). Only Hispaniolan amazons

264 reached relative abundances close to that found in large cities in two natural habitats (tropical

265 rain and dry forests, see table 1). Regarding the Jamaican parakeet, we only recorded this species

266 through systematic roadside surveys in two localities of Sierra de Bahoruco (Figure 2), totaling

26713 individuals. The scarcity of this species precluded an examination of its habitat-related

268 abundances.

269

270

271

272

273

274

275

276

277

278

279

280

281

282

283

284

285

286

287

288

289

290

291

The low number of contacts obtained through the systematic roadside surveys in habitats other than cities (Table 1) led us to pool habitats into three categories for statistical analyses: 1) large cities, 2) rural habitats (grouping villages and farmland, i.e., a mosaic of small villages and houses embedded in agricultural lands), and 3) natural habitats (grouping coniferous, tropical rainforest and tropical dry forests) (see Methods). The models obtained showed a strong effect of habitat on the abundance of both wild Hispaniolan parakeets and amazons while controlling for the length of each sub-transect surveyed (Table 2). The resulting estimated marginal means indicate a very low abundance of both species in rural habitats, while their abundance was six times higher in cities than in natural habitats in the case of the Hispaniolan parakeet and three times higher in the case of the Hispaniolan amazon (Table 3).

We censused the urban communal roost of Hispaniolan parakeets in Santo Domingo found by one of the authors (AL) in 2016, and recorded 1,580 individuals at sunset. We could not find the urban communal roost for this species in Santiago, but we found a roost of Hispaniolan amazons with about 50 individuals. We were informed of only one communal roost in natural habitats, located in Sierra de Bahoruco, one of the best-preserved areas in the country, where we only counted 137 Hispaniolan parakeets, 15 Hispaniolan amazons and 7 Jamaican parakeets gathering together at sunset (Figure 2).

\section{Conservation threats}

Regarding the perception of local people of the threats and conservation status of parrots, people living in 12 distant villages located in natural areas said that parrots were abundant in the past but that they are currently extinct in their area due to overharvesting. They indicated that it is now necessary to travel to the most inaccessible sites within protected areas in order to view or poach parrots. Three people also living in distant natural areas indicated that hunting as a food 
292 source was the main cause of decline of parrots. They described how parakeets and amazons are

293 considered game species (despite prohibition of this activity) and that large flocks were often

294 hunted for food coinciding with the shooting of massive numbers of several species of pigeons.

295 Moreover, one farmer explained how both parakeets and amazons are often killed to avoid crop

296 damage, using guns and glue traps.

297 Regarding the illegal pet trade, we found 131 parrots in captivity (66 Hispaniolan parakeets, 63

298 Hispaniolan amazons, and 2 Jamaican parakeets; Figure 1) thanks to the help of 51 persons

299 living in 20 different villages and cities. Owners knew that keeping wild parrots as pets is an

300 illegal activity, so in all cases but one pets were hidden inside their homes. Our visual

301 examination of the plumage and growth stage of these parrots allowed us to determine that most

302 of them $(74.8 \%)$ were juvenile birds that were poached a few weeks or months prior to our visit.

303 Attending to information provided by owners, the rest of the parrots were captured on average

3044.4 years ago (range: $1-25 \mathrm{yr}$ ). They also informed us that most parrots were poached as chicks

$305(96.7 \%)$, often by cutting the nesting tree to gain access to the nest, while the rest were captured

306

307

308

309

310

311

312

313

314

315

316

317

318

319

320 as adults using glue traps placed in crops. Parrot keepers also provided information on the areas where 110 parrots were poached. In most cases $(95.45 \%)$, parrots were poached within six protected areas (mostly in Bahoruco and Jaragua National Parks, 59\% and 14\% respectively) of the Dominican Republic, while four parrots were poached in the neighboring country (Haiti). Poached parrots were sold in the villages surrounding protected areas but also were transported to distant cities for sale in local markets. Pet owners said they prefer the Hispaniolan amazon over parakeets due to their ability to imitate human speech. This fact, together with the greater scarcity of amazons in the wild (see above), makes the average price of amazons indicated by pet owners (63.5 USD, range: 10.7 - 139 USD, $n=45$ ) twice as high as that of parakeets (31 USD, range: 10.7 - 64 USD, $n=15)$, to the point that in two cases poachers sold very young parakeets as amazons.

\section{Seed dispersal}

We observed the three species of parrots feeding on a total of 19 plant species from 11 families of trees and palms, of which 14 species $(74 \%)$ were dispersed by parrots by transporting fruits in 
321 their beaks to distant perching sites (Table 4). Five of the dispersed plant species were non-native

322 to Hispaniola Island (Table 4). Given the scarcity of parrots in rural and natural habitats, all but

323 one of the dispersal events was recorded in cities. We did not observe other species capable of

324 dispersing these fruits through stomatochory in the urban areas surveyed. The structure of

325 forested urban areas, urban parks and gardens mixed among buildings made it difficult to

326 measure seed dispersal frequencies and exact dispersal distances (e.g., we could observe an

327 amazon carrying a fruit in the beak but could not determine the exact tree from which the fruit

328 was picked). We thus looked for trees in which both amazons and parakeets perched to handle

329 and consume the fruits, and obtained minimum dispersal distances as the distance from each

330 discarded seed to the nearest fruiting plant of the same species. In this way, we recorded 306

331 dispersed seeds under 66 perching sites, corresponding to 11 plant species (Figure 3). In 99.5\%

332 of the cases, undamaged mature seeds were discarded after pulp consumption by parrots, thus

333 maintaining the potential for germination, with the rest being damaged or unripe seeds. The

334 median minimum dispersal distance was $37 \mathrm{~m}$ (range: 8 - $155 \mathrm{~m}$, Figure $3 \mathrm{~A}$ ). Most of the seeds

335 (93.85\%) were dispersed to minimum distances ranging between 20 and $60 \mathrm{~m}$, while only a

336 small fraction (4.85\%) was dispersed $>60 \mathrm{~m}$ (Figure 3A). Minimum dispersal distances varied

337 among plant species (Figure 3B), but differences were not statistically significant (Kruskall-

338 Wallis test, $\left.\varkappa^{2}=9.95, \mathrm{df}=9, \mathrm{p}=0.35\right)$.

\section{Discussion}

340 Large-scale parrot population declines

341 Our large-scale field survey, conducted at the end of the breeding season (Latta et al. 2006) when 342 parrot population sizes are expected to be the largest due to the recent recruitment of fledglings, 343 shows an extremely low abundance of the two parrot species endemic to Hispaniolan Island in 344 their natural habitats. Their scarcity in the wild is striking when compared to the abundances of 345 congeneric species we obtained following the same methodology in other Neotropical habitats.

346 The relative abundance of Hispaniolan parakeets in natural habitats (Table 3) resulted one order

347 of magnitude lower than that of blue-crowned parakeets (Tecthocercus (=Psittacara)

348 acuticaudatus, with an abundance $\mathrm{x} 47$ times higher) and mitred parakeets (Psittacara mitratus, 349 x25.8 times higher) in Bolivian Andean dry forests (Blanco et al. 2015), and white-eyed 350 parakeets (Psittacara leucophthalmus, x57.8 times higher) in Brazilian Atlantic forests (Tella et 
351 al. 2016b). On the other hand, the relative abundance in natural habitats of the Hispaniolan

352 amazon resulted one to two orders of magnitude lower than that of two amazon species also

353 listed by IUCN as Vulnerable, the red-spectacled amazon (Amazona pretrei, x109 times higher)

354 and the vinaceus amazon (Amazona vinacea, x23 times higher), in the Atlantic Brazilian forests

355 (Tella et al. 2016b). Even the blue-fronted amazon (Amazona aestiva) living in the inter-Andean

356 valleys of Bolivia, where populations are suffering from strong poaching pressure for the

357 domestic pet trade (Pires et al. 2016), showed a relative abundance 3.3 times higher (Blanco et

358 al. 2015) than the Hispaniolan amazon.

359

360

361

362

363

364

365

366

367

368

369

370

371

372

373

374

375

376

377

378

379

380

The current low abundance of Hispaniolan parrots cannot be attributed to island versus continental environmental conditions, as densities of bird species are often higher on islands than on the mainland (Newton 2003), but rather to a long-term process of human-induced population decline. Hispaniolan amazons and parakeets were known to form flocks of hundreds and thousands, respectively, until 1930, with the recent decline attributed to habitat loss, hunting and trapping for the pet trade (Latta et al. 2006). It is worth noting that the low abundances we obtained in natural habitats cannot be explained by habitat loss, since they were mostly obtained within protected and remote areas where the habitat still is reasonably well conserved. On the other hand, hunting and trapping have been at play for centuries. The Amerindians already trapped parrots for household pets and hunted them as they were highly appreciated as a food source, and Spanish colonists also hunted and traded parrots to the point of causing the extinction of one species (Wiley \& Kirwan 2013).

As a matter of concern, hunting and trapping are still threatening parrot populations. Both species of parrots formed large flocks in the past that probably moved through the island while tracking food resources (Latta et al. 2006). According to our conversations with local people, they were often killed for food during the post-breeding season coinciding with the massive hunting of very large flocks of pigeons, which gathered in coniferous forests during pine fructification. The access to modern guns probably accelerated the decimation of both parrots and pigeons; in fact, we only observed seven of the ten pigeon species occurring in Hispaniola Island, and always in very low numbers. Moreover, the loss of natural habitats by agriculture may have increased crop damage by parrots and thus motivated the shooting and trapping of parrots in agricultural lands. This may explain their lowest abundance in rural habitats, despite 
381 the high food availability in the form of cereal crops and fruiting trees surrounding small 382 villages.

Parrots are long-lived species with slow reproduction rates (Young et al. 2012), and

384

385

386

387

388

389

390

391

392

393

394

395

396

397

398

399

400

401

402

403

404

405

406

407

408

409 thus the overharvesting of adults (through hunting and trapping) has a higher impact on population dynamics than nest poaching (Pires et al. 2016; Valle et al. 2018). Nest poaching to supply the pet trade has ancestral cultural roots in Hispaniola Island (Wiley \& Kirwan 2013; White et al. 2011). However, the human population and economic growth in recent decades may have increased its intensity and contributed to the decimation of wild parrot populations. Information provided by local people supports the results of our field survey: they indicated local extinctions and population reductions in natural areas, with the last wild populations currently restricted to the protected and more inaccessible areas to which poachers are now forced to travel to obtain chicks for illegal trade. The fact that the pet trade is still a thriving activity, despite the rarity of parrots in the wild and its prohibition since 2000, may be explained both by cultural influences maintaining a high demand for pets (White et al . 2011) and by the lucrative benefits.

Poachers may take risks since just two nests of amazons can yield monetary rewards equal to the average wage per month in the country (259 USD, http://www.salaryexplorer.com/salarysurvey.php?loc=61\&loctype=1\#disabled).

Our baseline survey suggests that the conservation status of the endemic Hispaniolan parrots is worse than previously thought (Latta et al. 2006, BirdLife International 2016a, b), and that these species could enter a vortex of extinction in the wild if current threats are not halted. We hope this work will encourage further, more detailed conservation-aimed research on the remaining wild populations, as well as the enforcement of current laws against hunting and parrot poaching and the creation of education and conservation programs, ideally involving local residents (White et al., 2011).

\section{Cities as conservation hotspots}

The scarcity of Hispaniolan parrots in natural habitats contrasts with their relatively high abundances in the two larger cities. Parrots are known to be good natural colonizers of urban habitats (Carrete \& Tella 2011), and the presence of urban parrots in the largest city (Santo Domingo) is known for at least three decades (Carlos Cano, com. pers. 2017). We found that 
410 cities offer sufficient resources, such as food (including a variety of native and exotic plants),

411 nesting sites (cavities in trees and historic buildings, Figure 1B) and safe roosting sites, allowing

412 parrots to develop their complete annual cycles within urban areas. After initial urban

413 colonization, ecological conditions differing between natural and urban habitats should explain

414 the largest abundance of parrots in cities. Predation release (i.e., the generally lower abundance

415 of avian predators in urban habitats, Díaz et al. 2013) has been shown to explain the positive

416 population growth of a bird species in the city up to much higher densities than in the

417 surrounding natural habitats (Rebolo-Ifrán et al. 2017). In the case of Hispaniolan parrots, the

418 few avian predator species are scarce and mostly prey on small birds (Latta et al. 2006), and thus

419 humans can be considered as the main "predators" of parrots through hunting and trapping of

420 adults and nest poaching. These illegal activities are undoubtedly hampered in populated cities,

421 where moreover people may be more prone to conserving parrots. The same predator-release

422 mechanism could explain the proliferation in cities of an introduced exotic pigeon (Luna et al.

423 2018), in contrast to the poor conservation status of native pigeons due to hunting (Latta et al.,

424 2006). In addition to natural colonization and intrinsic growth of predator-free urban populations,

425 the release of parrots in cities may be reinforcing them; some pets could escape from cages,

426 and 28 Hispaniolan parrots and 132 Hispaniolan parakeets seized by the police have been

427 released in Santo Domingo since 2011 after being recovered in the city’s zoo (Marielis Sánchez,

428 com. pers. 2017).

Whatever the mechanisms for explaining urban parrot populations, large cities now constitute key conservation hotspots for these two endemic, globally threatened parrots.

431 Particularly, Santo Domingo could hold the largest world population of Hispaniolan parakeets, which we estimated at c. 1,600 individuals after censusing the only known communal roost that most likely concentrates all parakeets living in the city. As recently claimed for several threatened Australian species (Ives et al., 2016), national conservation policies should integrate urban populations when planning for and managing these threatened parrots. Conservationists and policymakers need to understand the opposing trends of natural and urban populations, since the flourishing urban populations may mask the poor conservation status of the species in the wild. 


\section{Conserving species and their ecological functions}

442 The importance of not only saving species but also their ecological functions from extinction is

443 gaining increasing support (Valiente-Banuet et al. 2015), to the point that some have claimed that

444 rewilding management actions should include the introduction of non-native species that are

445 functionally similar to extinct ones (Corlett 2016). The conservation value of some non-native

446 urban populations of threatened parrots (Gibson \& Yong 2017; Mori et al. 2017) has been

447 recently highlighted, as they can be viewed as genetic and population stocks for conservation

448 programs rather than just as invasive species (Gibson \& Yong 2017). This is a valuable

449 conservation argument but does not take into account that ecological functions of parrots may be

450 lost in nature if they are confined to cities, both within and outside of their native ranges. This is

451 likely because their ecological functions, other than their role as plant antagonists, have been

452 largely overlooked until recently (Blanco et al. 2018).

Despite the short-term nature of our baseline survey, we were able to demonstrate that

454

455

456

457

458

459

460

461

462

463

464

465

466

467

468

Hispaniolan parrots are legitimate long-distance seed dispersers of most of their food plant species, as they frequently transport fruits to distant perching trees where they discard undamaged seeds after fruit consumption. These results should be taken with caution, since most seed dispersal records were obtained from food plants growing in urban habitats. Unfortunately, to our knowledge there are no studies focusing on the diet and foraging behaviour of these species in the wild. However, it is reasonable to expect Hispaniolan parrots are also acting as frequent seed dispersers in natural habitats, as we have recently shown for other parrot-plant systems (Blanco et al. 20015, 2018; Tella et al. 2015, 2016a, 2016b; Baños-Villalba et al. 2017; Montesinos-Navarro et al. 2017). Notably, parrots are also covering an important ecological function in urban environments, but with the undesirable side effect of often spreading exotic plant species (see Table 4). On the other hand, it is worth noting that we only focused on the easily observed external dispersal (stomatochory), while internal dispersal through the ingestion and defecation of small viable seeds (endozoochory) is also expected to occur as in other parrot species (Blanco et al. 2016). Other mutualistic functions of Hispaniolan parrots can be also expected, such as pollination, food wastage that facilitates secondary dispersal and food for 
469 terrestrial animals, and the consumption of plant parasites (Montesinos-Navarro et al. 2017;

470 Blanco et al. 2018).

471 Parrots have been shown to be key dispersers of some plant species in contrasting 472 ecosystems (Boehning-Gaese et al. 1999; Blanco et al. 2015; Tella et al. 2016a, 2016b; Baños473 Villalba et al. 2017), and their regional or global extinction may disrupt ecological processes 474 with uncertain consequences (Blanco et al. 2018). One of the ecological functions most affected 475 by the decline of plant-animal mutualisms is seed dispersal (Howe \& Smallwood, 1982), in the 476 way that the disruption of disperser-plant interactions can trigger declines in plant diversity 477 (Cordeiro \& Howe, 2003), seedling recruitment (Terborgh et al. 2008), and gene flow in 478 fragmented landscapes (González-Varo et al. 2017). Disruptions of seed dispersal by habitat loss 479 and defaunation can be more dramatic in the case of islands (Traveset et al. 2012; Fontúrbel et al. 480 2017), given a generally lower species diversity than in the mainland (Newton 2003) and thus a 481 higher probability of losing functionally non-redundant species (Valiente-Banuet et al. 2015). In 482 the case of Hispaniola Island, the only large-sized species feeding on fruits are one trogon and 483 two crow species, which are scarce and threatened, while the rest are small passerines (Latta et. 484 al 2006). These smaller-sized species are expected to only disperse tiny seeds through 485 endozoochory, and thus parrots are probably the only species capable of dispersing the seeds of 486 plants producing large fruits and seeds through stomatochory (see Blanco et al 2016). Therefore,

487 the loss of rare species performing rare functions, as may be the case of Hispaniolan parrots, may 488 have a stronger impact on ecosystem functioning (Violle et al. 2017). Unfortunately, the regional 489 and global extinction of these parrot species are not a mere possibility, but a likely fact. Parrot 490 populations began a strong decline in the Caribbean islands upon European colonization due to 491 habitat loss, hunting and the pet trade (Wiley, 1991), to the point that endemic macaws 492 inhabiting up to 11 islands were all extinct by the 1850s (Wiley \& Kirwan 2013), as well as 493 subspecies of the Hispaniolan parakeet endemic to Puerto Rico (by 1900), the Guadeloupe 494 amazon (Amazona violacea) and the Martinique amazon (Amazona martinicana) were extinct as 495 a result of hunting (by the end of the $18^{\text {th }}$ century), while 10 out of the 13 extant Caribbean parrot 496 species are globally threatened (IUCN 2017).

\section{Conclusions}


498 If current trends continue, approximately 5 billion of the world's 8 billion residents will live in

499 cities by 2030, with projections of nearly 6 million square kilometers of land converted to urban

500 areas (Seto et al. 2012). This global urbanization process will increase the negative impacts on

501 biodiversity through habitat loss (Seto et al. 2012; Newbold et al. 2015), but also the role of

502 cities as conservation hotspots for a number of threatened species that perform better there than

503 in their natural habitats (Rebolo-Ifrán et al. 2017). Our example using Hispaniolan parrots as a

504 case study may reflect many others, currently overlooked or expected in the near future, given

505 the widespread human impact on parrot populations through habitat loss and overharvesting

506 (Tella \& Hiraldo 2014; Olah et al. 2016; Berkunsky et al. 2017). On the other hand, the role of

507 Hispaniolan parrots as seed dispersers should not come as a surprise, given the variety of

508 ecological functions of parrots that have gone unrecognized until recently (Blanco et al. 2017).

509 Therefore, although conservation planning should seriously consider the value of urban

510 populations of parrots and many other threatened taxa (Ives et al. 2016; Gibson \& Yong 2017), it

511 should not distract efforts to restore their populations in natural habitats to conserve their

512 ecological functions. In fact, the loss of ecosystem functions and services through local

513 biodiversity loss should be given as much attention as the rate of species extinction in the current

514 scenario of global change (Newbold et al. 2012).

\section{Acknowledgements}

516 Thanks to Cyntia Ortiz of the Ministry for her help during the preliminary stages of the

517 expedition, to the people from Asociación Jaragua for their help in the field, to the National

518 Botanical Garden of Dominican Republic for the identification of plants, and to the National

519 Zoological Park for their advice and information. We are also grateful to David Aragonés

520 (LAST-EBD) for helping us to elaborate the map. Two anonymous reviewers greatly helped to 521 improve our manuscript.

522

523

524

525 


\section{References}

530

531

532

533

534

535

536

537

538

539

540

541

542

543

544

545

546

547

548

549

550

551

552

553

554

Abellán P, Tella, J, Carrete M, Cardador L, Anadón JD. 2017. Climatic matching drives spread rate but not establishment success in recent unintentional bird introductions. PNAS 201704815 doi: $10.1073 /$ pnas. 1704815114

Annorbah NN, Collar NJ, Marsden SJ .2016. Trade and habitat change virtually eliminate the Grey Parrot Psittacus erithacus from Ghana. Ibis 158: 82-91.

Aronson MFJ, LaSorte FA, Nilon CH, Katti M,. Goddard MA, Lepczyk CA, Warren PS, Williams NSG, Cilliers S, Clarkson B, Dobbs C, Dolan R, Hedblom M, Klotz S, Kooijmans JL, Kühn I, MacGregor-Fors I, McDonnell M, Mörtberg U, Pyšek P, Siebert, Sushinsky J, Werner P, Winter M. 2014. A global analysis of the impacts of urbanization on bird and plant diversity reveals key anthropogenic drivers. Proceedings of the Royal Society B: Biological Sciences, 281, 20133330. doi: 10.1098/rspb.2013.3330

Baños-Villalba A, Blanco G, Díaz-Luque JA, Dénes FV, Hiraldo F, Tella JL. 2017. Seed dispersal by macaws shapes the landscape of an Amazonian ecosystem. Scientific Reports, 7. https://doi.org/10.1038/s41598-017-07697-5

Berkunsky I, Quillfeldt P, Brightsmith DJ, Abbud MC, Aguilar JMRE, Alemán U, Aramburú RM, Arce Arias A, Balas McNab R, Balsby TJS, Barredo Barberena JM, Beissinger SR, Benito de Franco MR, Berg KS, Bianchi CA, Blanco E, Bodrati A, Bonilla Ruz C, BoteroDelgadillo E, Canavelli SB, Caparroz R,Cepeda RE, Chassot O, Cinta CC, Cockle K, Daniele G, de Araujo CB, deBarbosa AE, de Moura LN, Del Castillo H, Díaz S, DíazLuque JA, Douglas L, Figueroa Rodríguez A, García-Anleu R, Gilardi JD, Grilli PG, Guix JC, Hernández M, Hernández-Muñoz A, Hiraldo F, Horstman E, Ibarra Portillo R, Isacch JP, Jiménez JE, Joyner L, Juarez M, Kacoliris FP, Kanaan VT, Klemann-Júnior L, Latta SC, Lee ATK, Lesterhuis A, Lezama-López M, Lugarini C, Marateo G, Marinelli CB, Martínez J, McReynolds MS, Mejia Urbina CR, Monge-Arias G, Monterrubio-Rico TC, Nunes AP, Nunes FdP, Olaciregui C, Ortega-Arguelles J, Pacifico E, Pagano L, Politi N, 
555

556

557

558

559

560

561

562

563

564

565

566

567

568

569

570

571

572

573

574

575

576

577

578

579

580

581

582

583

584

585

Ponce-Santizo G, Portillo Reyes HO, Prestes NP, Presti F, Renton K, Reyes-Macedo G, Ringler E, Rivera L, Rodríguez-Ferraro, A, Rojas AA, Rojas-Llanos RE, Rubio-Rocha YG, Saidenberg ABS, Salinas-Melgoza A, Sanz V, Schaefer HM, Scherer-Neto P, Seixas GHF, Silveira LF, Sipinski EAB, Somenzari M, Susanibar D, Tella JL, Torres-Sovero C, Vargas-Rodríguez R, Vázquez-Reyes LD, White Jr TH, Williams S, Zarza R, Masello JF. 2017. Current threats faced byNeotropical parrot populations. Biological Conservation 214: 278-287. https://doi.org/10.1016/j.biocon.2017.08.016

BirdLife International. 2016a. Amazona ventralis. The IUCN Red List of Threatened Species 2016: e.T22686215A93103000. http://dx.doi.org/10.2305/IUCN.UK.20163.RLTS.T22686215A93103000.en.

BirdLife International. 2016b. Psittacara chloropterus. The IUCN Red List of Threatened Species 2016: e.T22685695A93083622. http://dx.doi.org/10.2305/IUCN.UK.20163.RLTS.T22685695A93083622.en.

BirdLife International. 2016c. Eupsittula nana. The IUCN Red List of Threatened Species 2016 : e.T45418540A95147758. http://dx.doi.org/10.2305/IUCN.UK.20163.RLTS.T45418540A95147758.en.

Blanco G, Hiraldo F, Rojas A, Dénes FV, Tella JL. 2015. Parrots as key multilinkers in ecosystem structure and functioning. Ecology and evolution, 5(18), 4141-4160. http://dx.doi.org/10.1002/ece3.1663

Blanco G, Bravo C, Pacífico E, Chamorro D, Speziale K, Lambertucci S, Hiraldo F, Tella JL. 2016. Internal seed dispersal by parrots: an overview of a neglected mutualism. PeerJ, 4: e1688 https://doi.org/10.7717/peerj.1688

Blanco G, Hiraldo F, Tella JL. 2018. Ecological functions of parrots: an integrative perspective from plant life cycle to ecosystem functioning. Emu-Austral Ornithology, 118, 36-49.

Boehning-Gaese K, Gaese BH, Rabemanantsoa SB. 1999. Importance of primary and secondary seed dispersal in the Malagasy tree Commiphora guillaumini. Ecology, 80, 821-832. doi: 10.1890/0012-9658(1999)080[0821:IOPASS]2.0.CO;2

Cardador L, Lattuada M, Strubbe D, Tella JL, Reino L, Figueira R, Carrete M. 2017. Regional bans on wild-bird trade modify invasion risks at a global scale. Conservation Letters,00(00), 1-9. doi: 10.1111/conl.12361

Chace JF, Walsh JJ.2006. Urban effects on native avifauna: a review. Landscape and urban 
586

587

588

589

590

591

592

593

594

595

596

597

598

599

600

601

602

603

604

605

606

607

608

609

610

611

612

613

614

615

616

planning, 74(1), 46-69. https://doi.org/10.1016/j.landurbplan.2004.08.007

Cordeiro NJ, Howe HF. 2003. Forest fragmentation severs mutualism between seed dispersers and an endemic African tree. Proceedings of the National Academy of Sciences of the United States of America, 100:14052-14056. http://www.jstor.org/stable/3148910

Corlett RT. 2016. Restoration, reintroduction, and rewilding in a changing world. Trends in ecology \& evolution, 31(6), 453-462. https://doi.org/10.1016/j.tree.2016.02.017

Dearborn DC, Kark S.2010. Motivations for conserving urban biodiversity. Conservation biology, 24(2), 432-440. doi: 10.1111/j.1523-1739.2009.01328.x

Dénes F, Tella JL, Beissinger SR. 2018. Revisiting methods for estimating parrot abundance and population size. Emu - Austral Ornithology, 118, 67-79.

Díaz M, Møller AP, Flensted-Jensen E, Grim T, Ibáñez-Álamo JD, Jokimäki J, Markó G.Tryjanowski P. 2013. The geography of fear: a latitudinal gradient in anti-predator escape distances of birds across Europe. PloS one, 8(5), p.e64634. https://doi.org/10.1371/journal.pone.0064634

Fitzsimons J, Palmer GC, Antos MJ,White J. 2003. Refugees and residents: densities and habitat preferences of lorikeets in urban Melbourne. Australian field ornithology, 20, 2-7. http://dro.deakin.edu.au/view/DU:30001873

Fontúrbel FE, Jordano P, Medel R. 2017. Plant-animal mutualism effectiveness in native and transformed habitats: Assessing the coupled outcomes of pollination and seed dispersal. Perspectives in Plant Ecology, Evolution and Systematics, 28, 87-95. https://doi.org/10.1016/j.ppees.2017.09.003

Gibson L,Yong DL. 2017. Saving two birds with one stone: solving the quandary of introduced, threatened species. Frontiers in Ecology and the Environment, 15(1), 35-41. doi: $\underline{10.1002 / \text { fee. } 1449}$

González-Oreja JA. 2010. Birds of different biogeographic origins respond in contrasting ways to urbanization. Biological Conservation 144, 234-242 https://doi.org/10.1016/j.biocon.2010.08.021

González-Varo JP, Carvalho CS, Arroyo JM, Jordano P. 2017. Unravelling seed dispersal through fragmented landscapes: Frugivore species operate unevenly as mobile links. Molecular Ecology. 26(16), 4309-4321. http://dx.doi.org/10.1111/mec.14181

Grilli PG, Soave GE, Arellano ML, Masello JF. 2012. Abundancia relativa del Loro Barranquero 
617 (Cyanoliseus patagonus) en la provincia de Buenos Aires y zonas limítrofes de La Pampa 618 y Río Negro, Argentina. El hornero. 27, 63-71.

619 Grimm NB, Faeth SH, Golubiewski NE, Redman CL, Wu J, Bai X, Briggs JM. 2008. Global 620 change and the ecology of cities. Science, 319(5864), 756-760.

$621 \quad$ http://www.jstor.org/stable/20053310

622 Howe HF, Smallwood J. 1982. Ecology of seed dispersal. Annual Review of Ecology and 623 Systematics, 13, 201-228. https://doi.org/10.1146/annurev.es.13.110182.001221

624 IUCN 2017. The IUCN Red List of Threatened Species. Version 2017-2.

$625 \quad<$ http://www.iucnredlist.org $>$.

626 Ives CD, Lentini PE, Threlfall CG, Ikin K, Shanahan DF, Garrard GE, Rowe R. 2016. Cities are 627

628 http://dx.doi.org/10.1111/geb.12404 hotspots for threatened species. Global Ecology and Biogeography, 25(1), 117-126.

629 Kark S, Iwaniuk A, Schalimtzek A, Banker E. 2007. Living in the city: can anyone become an 630 631 'urban exploiter'?. Journal of Biogeography, 34(4), 638-651. doi: 10.1111/j.1365$\underline{2699.2006 .01638 . x}$

Latta S, Rimmer C, Keith A, Wiley J, Raffaele HA, McFarland K, Fernandez E. 2006. Aves de la República Dominicana y Haití. Princeton University Press.

Luna A, Romero-Vidal P, Hiraldo F, Tella JL. 2018. Cities favour the recent establishment and current spread of the Eurasian collared dove Streptopelia decaocto (Frivaldszky, 1838) in Dominican Republic. BioInvasion Records

Mason CF.2010. Thrushes now largely restricted to the built environment in eastern England. Diversity and distributions, 6(4), 189-194. http://www.jstor.org/stable/2673424

McKinney ML. 2006. Urbanization as a major cause of biotic homogenization. Biological Conservation. 127, 247-260. https://doi.org/10.1016/j.biocon.2005.09.005

Miller JR, Hobbs RJ. 2002. Conservation where people live and work. Conservation biology, 16(2), 330-337. http://www.jstor.org/stable/3061359

Montesinos-Navarro A, Hiraldo F, Tella JL, Blanco G. 2017. Network structure embracing mutualism-antagonism continuums increases community robustness. Nature Ecology and Evolution, p. 1. doi:10.1038/s41559-017-0320-6

Mori E, Grandi G, Menchetti M, Tella JL, Jackson HA, Reino L, Van Kleunen A, Figueira R, Ancillotto L. 2017. Worldwide distribution of non-native Amazon parrots and temporal 
648

649

650

651

652

653

654

655

656

657

658

659

660

661

662

663

664

665

666

667

668

669

670

671

672

673

674

675

676

677

678

trends of their global trade. Animal Biodiversity and Conservation 40: 49-62.

Newbold T, Hudson LN, Hill SL, Contu S, Lysenko I, Senior RA, Börger L, Bennett DJ, Choimes A, Collen B, Day J, 2015. Global effects of land use on local terrestrial biodiversity. Nature 520, 45-50. doi:10.1038/nature14324

Newton I. 2003. The speciation and biogeography of birds. Academic Press, London.

Olah G, Butchart SH, Symes A, Guzmán IM, Cunningham R, Brightsmith DJ, Heinsohn R. 2016. Ecological and socio-economic factors affecting extinction risk in parrots. Biodiversity and conservation, 25(2), 205-223. https://doi.org/10.1007/s10531$\underline{015-1036-\mathrm{Z}}$

Olivo EA. 2007. Historia de la producción agropecuaria y forestal en la República Dominicana. Editora Universal.

Pires S, Herrera M, Tella JL. 2016. Spatial, temporal and age sources of variation in parrot poaching in Bolivia. Bird Conservation International 26: 293-306.

Rebolo-Ifrán N, Tella JL, Carrete M. 2017. Urban conservation hotspots: predation release allows the grassland-specialist burrowing owl to perform better in the city. Scientific Reports, 7, 3527. https://doi.org/10.1038/s41598-017-03853-z

Seto KC, Güneralp B, Hutyra LR. 2012. Global forecasts of urban expansion to 2030 and direct impacts on biodiversity and carbon pools. Proceedings of the National Academy of Sciences, 109(40), 16083-16088. doi: 10.1073/pnas.1211658109

Sol D, Gonzalez-Lagos C, Moreira D, Maspons J. 2014. Urbanisation tolerance and the loss of avian diversity. Ecology Letters, 17, 942-950. doi: 10.1111/ele.12297

Speziale KL, Lambertucci SA, Gleiser G, Tella JL, Hiraldo F, Aizen MA. 2018. An overlooked plant-parakeet mutualism counteracts human overharvesting on an endangered tree. Royal Society open science, 5(1), 171456.

Tella JL, Rojas A, Carrete M, Hiraldo F. 2013. Simple assessments of age and spatial population structure can aid conservation of poorly known species. Biological Conservation, 167, 425-434. https://doi.org/10.1016/j.biocon.2013.08.035

Tella JL, Hiraldo F. 2014. Illegal and legal parrot trade shows a long-term, cross-cultural preference for the most attractive species increasing their risk of extinction. PLoS ONE 9 (9), e107546. $\quad$ https://doi.org/10.1371/journal.pone.0107546

Tella J L, Canale A, Carrete M, Petracci P, Zalba SM. 2014. Anthropogenic nesting sites allow 
679

680

681

682

683

684

685

686

687

688

689

690

691

692

693

694

695

696

697

698

699

700

701

702

703

704

705

706

707

708

709

urban breeding in burrowing parrots Cyanoliseus patagonus. Ardeola, 61(2), 311-321. https://doi.org/10.13157/arla.61.2.2014.311

Tella JL, Baños-Villalba A, Hernández-Brito D, Rojas A, Pacífico E, Díaz-Luque JA, Carrete M, Blanco G, Hiraldo F. 2015. Parrots as overlooked seed dispersers. Frontiers in Ecology and the Environment, 13(6), 338-339. http://dx.doi.org/10.1890/1540-9295$\underline{13.6 .338}$

Tella JL, Lambertucci S, Speziale K, Hiraldo F. 2016a. Large-scale impacts of multiple cooccurring invaders on monkey puzzle forest regeneration, native seed predators and their ecological interactions. Global Ecology and Conservation 6: 1-15. https://doi.org/10.1016/j.gecco.2016.01.001

Tella JL, Dénes FV, Zulian V, Prestes NP, Martínez J, Blanco G, Hiraldo F. 2016b. Endangered plant-parrot mutualisms: seed tolerance to predation makes parrots pervasive dispersers of the Parana pine. Scientific Reports 6, 31709. doi:10.1038/srep31709

Terborgh, J, Nunez-Iturri G, Pitman NCA, Valverde FHC, Alvarez P, Swamy V, Pringle EG, Paine CET. 2008. Tree recruitment in an empty forest. Ecology, 89:1757-1768. http://dx.doi.org/10.1890/07-0479.1

Traveset A., Gonzalez-Varo, JP,Valido A. 2012. Long-term demographic consequences of a seed dispersal disruption. Proceedings of the Royal Society of London B: Biological Sciences, 48(1), 1-9. https://doi.org/10.1098/rspb.2012.0535

Valiente-Banuet A, Aizen MA, Alcántara JM., Arroyo J, Cocucci A, Galetti M, García MB, García D, Gómez JM, Jordano P, Medel R. 2015. Beyond species loss: the extinction of ecological interactions in a changing world. Functional Ecology, 29, 299-307.doi: $\underline{10.1111 / 1365-2435.12356}$

Valle S, Collar NJ, Harris WE, Marsden SJ. 2018. Trapping method and quota observance are pivotal to population stability in a harvested parrot. Biological Conservation, 217, 428436.

Violle C, Thuiller W, Mouquet N, Munoz F, Kraft NJ, Cadotte MW, Livingstone SW, , Mouillot D. 2017. Functional Rarity: The Ecology of Outliers. Trends in Ecology \& Evolution.

White Jr TH, Camacho AJ, Bloom T, Diéguez PL, Sellares R. 2011. Human perceptions regarding endangered species conservation: A case study of Saona Island, Dominican Republic. Latin American Journal of Conservation, 2(1), 18-29. 
710 Wiley JW. 1991. Status and conservation of parrots and parakeets in the Greater Antilles,

711 Bahama Islands, and Cayman Islands. Bird Conservation International, 1(3), 187-214.

712 https://doi.org/10.1017/S095927090000059

713 Young AM, Hobson EA, Lackey LB, Wright TE. 2012. Survival on the ark: life-history trends in captive parrots. Animal Conservation 15: 28-43. doi: 10.1111/j.1469-1795.2011.00477.x reporting on interviews in conservation science research. Methods in Ecology and Evolution 9:10-19.

719 
720 Table 1. Raw results of the roadside survey, showing the number of km surveyed in each habitat, 721 the number of individuals (Nindiv), number of records (Nrec) and relative abundance (number of 722 individuals / km surveyed) obtained for the Hispaniolan parakeet (Psittacara chloropterus) and

723 Hispaniolan amazon (Amazona ventralis).

\begin{tabular}{lrrrrrrr}
\hline & \multicolumn{4}{c}{ P. chloropterus } & \multicolumn{3}{c}{ A. } \\
\hline Habitat & $\mathbf{k m}$ & Nindiv & Nrec & Indiv/km & Nindv & Nrec & Indiv/km \\
City & 370.34 & 262 & 38 & 0.70 & 25 & 10 & 0.06 \\
Village & 509.38 & 17 & 4 & 0.03 & 4 & 1 & $7.85 \times 10-3$ \\
Farmland & 375.39 & 12 & 1 & 0.03 & 1 & 1 & $2.66 \times 10^{-3}$ \\
Coniferous forest & 108.64 & 48 & 2 & 0.44 & 0 & 0 & 0.00 \\
Tropical rain forest & 314.46 & 70 & 10 & 0.22 & 19 & 3 & 0.06 \\
Tropical dry forest & 465.29 & 29 & 3 & 0.06 & 22 & 3 & 0.04 \\
TOTAL & 2143.5 & 438 & 58 & & 71 & 18 & \\
\hline
\end{tabular}


742 Table2. Results of generalized linear models showing differences among habitats in the

743 abundance of the two parrot species while controlling for the length (in $\mathrm{km}$ ) of each subtransect.

\begin{tabular}{lccccc} 
& Estimate & SE & $\mathbf{9 5 \%}$ CI & Wald $\boldsymbol{\mathcal { C }}^{2}$ & P \\
\hline P. chloropterus & & & & & \\
Intercept & -1.951 & 0.46 & {$[-2.85,-1.05]$} & 17.96 & 0.000 \\
City & 3.297 & 0.49 & {$[2.33,4.27]$} & 44.50 & 0.000 \\
Natural & 1.542 & 0.50 & {$[0.57,2.52]$} & 9.63 & 0.002 \\
Rural & 0 &. & $\cdot$ & $\cdot$ & $\cdot$ \\
Subtransect length & .039 & 0.01 & {$[0.03,0.05]$} & 40.28 & 0.000
\end{tabular}

$\begin{array}{lccccc}\text { A. ventralis } & & & & & \\ \text { Intercept } & -3.625 & 0.53 & {[-4.67,-2.58]} & 45.93 & 0.000 \\ \text { City } & 3.008 & 0.59 & {[1.85,4.17]} & 25.79 & 0.000 \\ \text { Natural } & 2.023 & 0.56 & {[0.92,3.12]} & 12.97 & 0.000 \\ \text { Rural } & 0 & . & . & . & . \\ \text { Subtransect length } & 0.031 & 0.01 & {[0.2,0.05]} & 17.78 & 0.000\end{array}$

745

746

747

748

749

750

751

752

753 
755

756 Table 3. Estimated marginal means obtained from generalized linear models (see Table 2) for

757 the relative abundance (number of individuals / $\mathrm{km}$ ) of each parrot species in different habitats.

758

\begin{tabular}{lcccc}
\cline { 2 - 5 } & \multicolumn{2}{c}{ A.ventralis } & \multicolumn{2}{c}{ P.chloropterus } \\
\cline { 2 - 5 } & mean & $\mathbf{9 5 \%}$ CI & mean & $\mathbf{9 5 \%}$ CI \\
\hline city & 0.096 & $0.056-0.164$ & 0.718 & $0.471-1,096$ \\
natural & 0.036 & $0.024-0.051$ & 0.124 & $0.082-0.187$ \\
rural & 0.004 & $0.001-0.012$ & 0.027 & $0.011-0.064$ \\
\end{tabular}

765

766

767

768

769

770

771

772

773

774 
776

777 Table 4. List of plant species and families of which we observed the three species of parrots

778 consuming and dispersing fruits. Asterisks indicate non-native plant species.

779

\begin{tabular}{|c|c|c|c|c|c|c|c|}
\hline \multirow[b]{2}{*}{ Plant species } & \multirow[b]{2}{*}{ Family } & \multicolumn{2}{|l|}{ A.ventralis } & \multicolumn{2}{|c|}{ P.chloropterus } & \multicolumn{2}{|l|}{ E.nana } \\
\hline & & Consumed & Dispersed & Consumed & Dispersed & Consumed & Dispersed \\
\hline Simarouba glauca & Simaroubaceae & & & & & Yes & Yes \\
\hline Adonidia merrillii*(Vitchia merrillii & Arecaceae & & & Yes & Yes & & \\
\hline Dypsis (Chrysalidocarpus) lutescens * & Arecaceae & & & Yes & Yes & & \\
\hline Prestoea acuminata & Arecaceae & & & Yes & Yes & & \\
\hline Roystonea (hispaniolana) borinquena & Arecaceae & & & Yes & Yes & & \\
\hline Sabal dominguensis & Arecaeae & Yes & & Yes & Yes & & \\
\hline Coccoloba uvifera & Polygonaceae & & & Yes & Yes & & \\
\hline Inga ruiziana (Gina sp) & Leguminosae & & & Yes & Yes & & \\
\hline Pithecellobium dulce & Leguminosae & Yes & & & & & \\
\hline Tamarindus indica* & Leguminosae & & & Yes & Yes & & \\
\hline Mangifera indica* & Anacardiaceae & Yes & & Yes & Yes & & \\
\hline Sapindus saponaria & Sapindaceae & & & Yes & Yes & & \\
\hline Melicoccus bijugatus & Sapindaceae & & & Yes & & & \\
\hline Terminalia catappa & Combretaceae & & & Yes & Yes & & \\
\hline Sideroxylon foetidissimum & Sapotaceae & Yes & & & & & \\
\hline Azadirachta indica & Meliaceae & Yes & Yes & Yes & & & \\
\hline Casuarina sp* & Casuarinaceae & Yes & & & & & \\
\hline Araucaria heterophylla* & Araucariaceae & & & Yes & & & \\
\hline Unknown & Unknown & Yes & Yes & & & & \\
\hline
\end{tabular}

\section{0}

781

782

783

784

785

786

787

788

789 
794

795 Figure 1. Three species of parrots occur in the Dominican Republic: A) the Hispaniolan amazon 796 (Amazona ventralis), B) the Hispaniolan parakeet (Psittacara chloropterus), and C) the Jamaican 797 parakeet (Eupsittula nana). The three species are illegally trapped for sale as pets (D, E and F, 798 respectively). Photographs taken by A. Luna (A ,C ,F) and J.L. Tella (B, D, E).

799

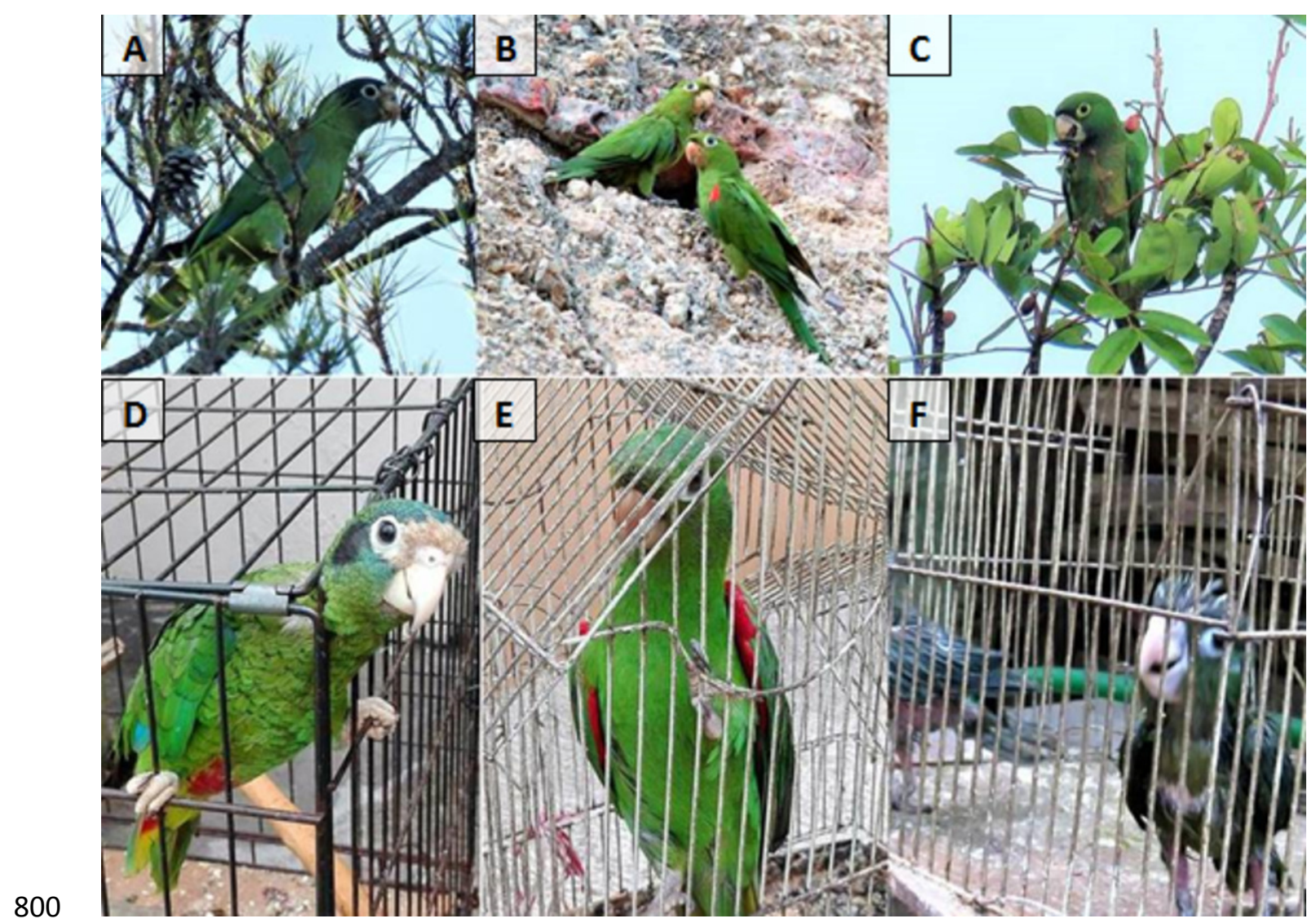

801

802 
806

807

808

809

810 Figure 2. A) Map of the Hispaniolan island including the roadside transects surveyed in

811 Dominican Republic (black lines, totaling $2134.5 \mathrm{kms}$ ), the records of Psittacara chloropterus

812 (white dots), Amazona ventralis (black triangles), both species together (black squares), and

813 Eupsittula nana (asterisks). Numbers 1, 2 and 3 show the location of communal roosts. B) and

814 C) show details for the main cities, Santiago and Santo Domingo, respectively. The main habitats 815 depicted (agriculture, natural and urban areas) were obtained from the Caribbean Land Cover 816 Project (https://lca.usgs.gov/carland/index.php).

817

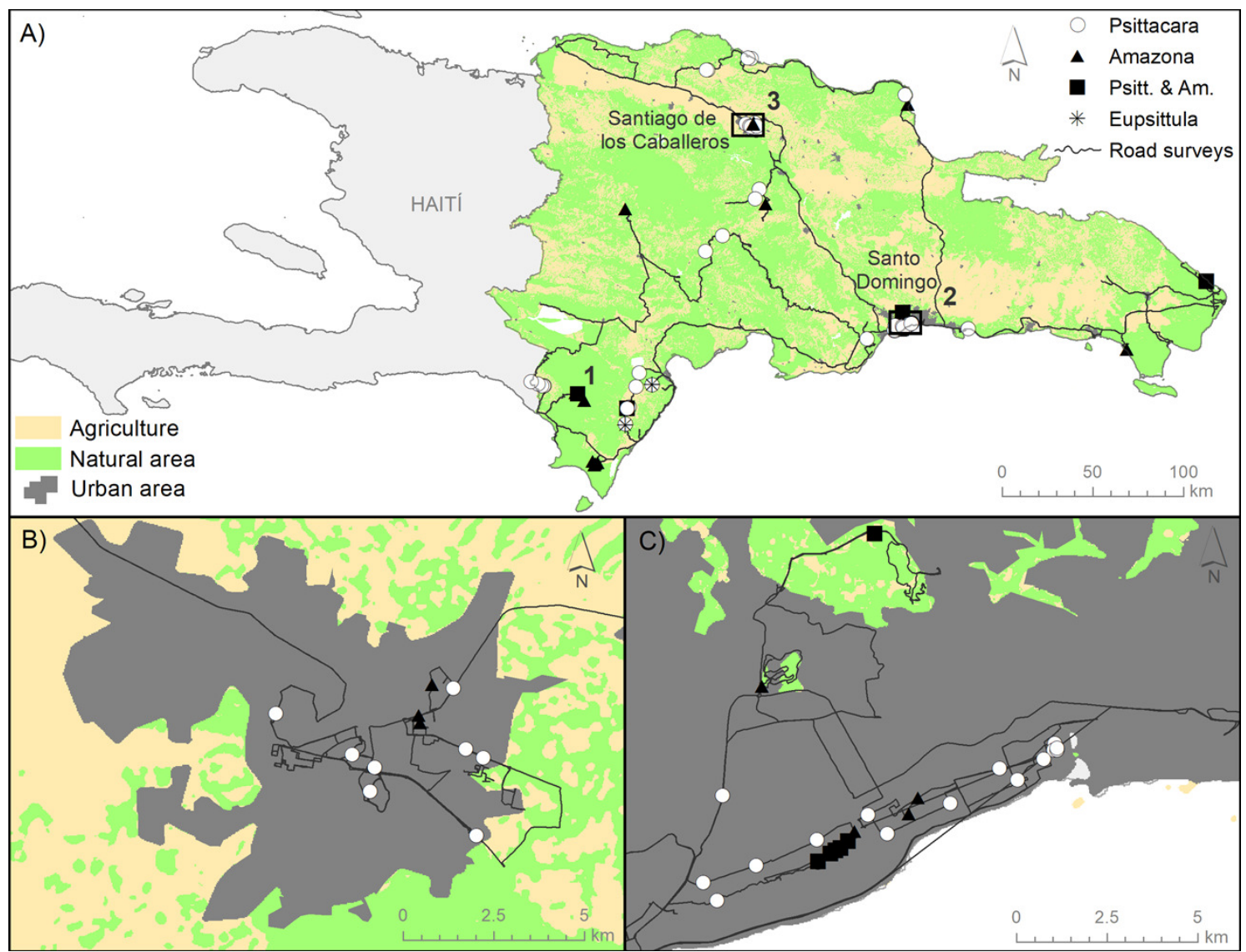


827 Figure3. (A) Proportion of seeds dispersed by parrots $(n=306)$ grouped into ten-meter distance 828 intervals. (B) Median dispersal distances for each plant species, with sample sizes indicated to 829 the right of the bars.

\section{0}

831

A 


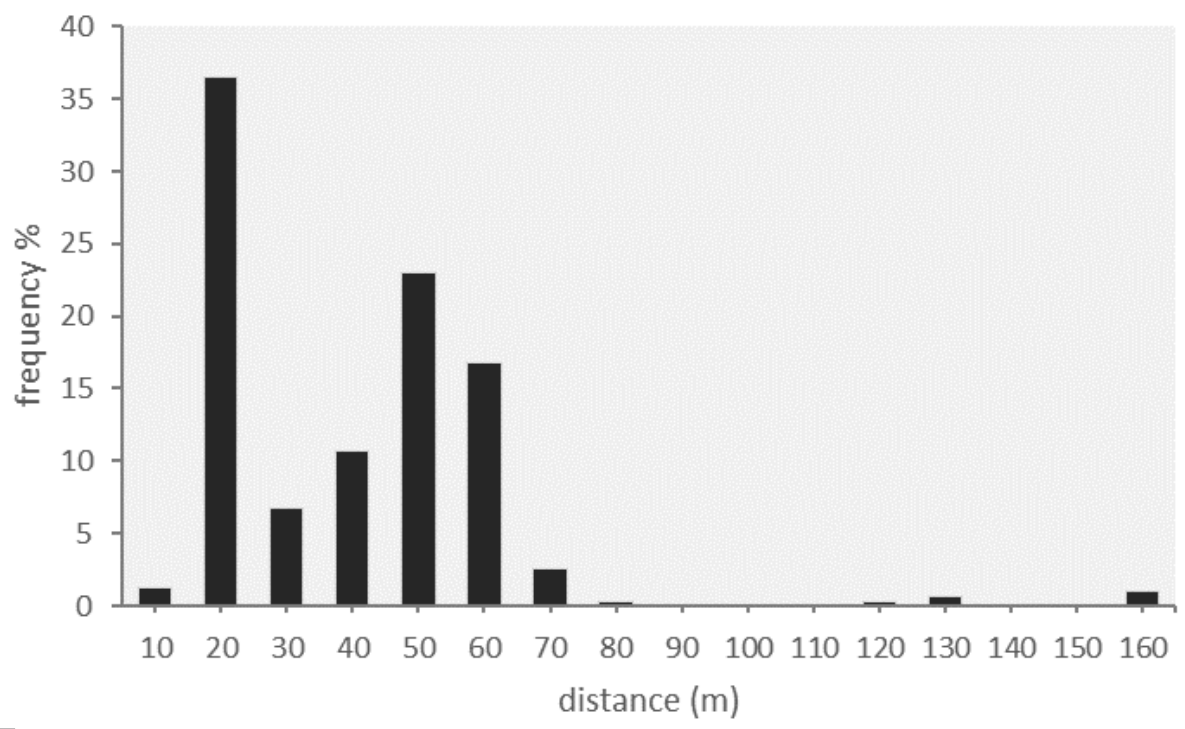

832

B

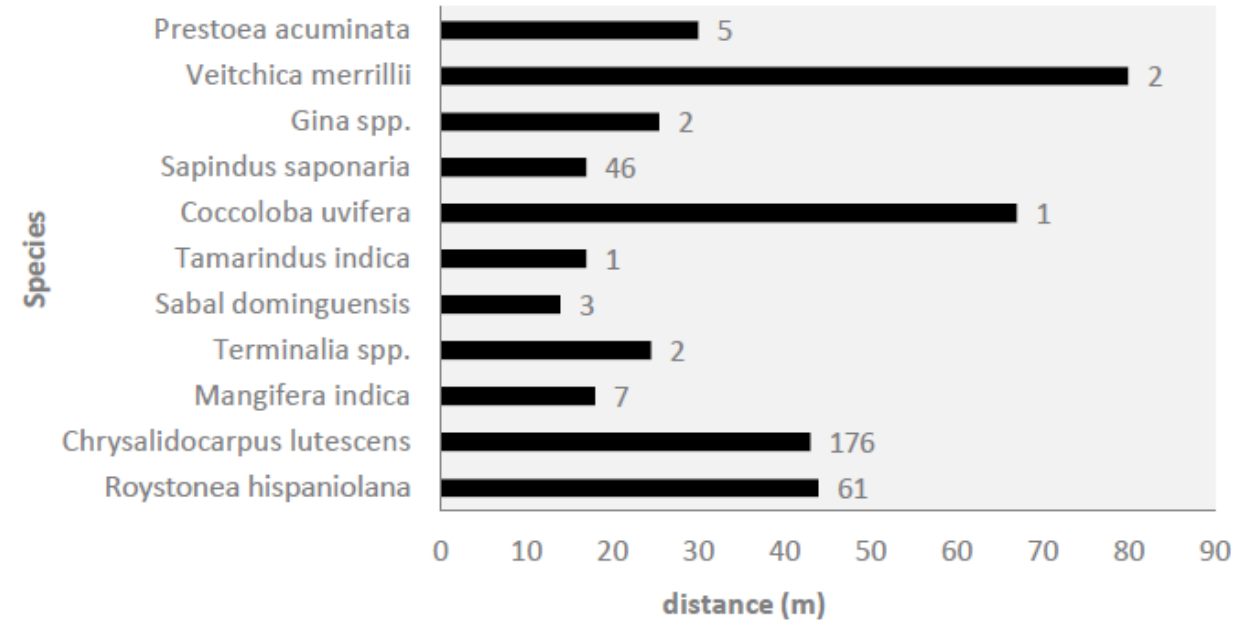

833 


\section{Table $\mathbf{1}$ (on next page)}

Raw results of the roadside survey

Number of km surveyed in each habitat, number of individuals (Nindiv), number of records (Nrec) and relative abundance (number of individuals $/ \mathrm{km}$ surveyed) obtained for the Hispaniolan parakeet (Psittacara chloropterus) and Hispaniolan amazon (Amazona ventralis). 


\begin{tabular}{|c|c|c|c|c|c|c|c|}
\hline \multirow{2}{*}{ Habitat } & \multicolumn{4}{|c|}{ P. chloropterus } & \multicolumn{2}{|c|}{ A. ventralis } & \multirow[b]{2}{*}{ Indv/km } \\
\hline & km & Nindv & Nrec & Indv/km & Nindv & Nrec & \\
\hline & 370.3 & 262 & 38 & 0.7 & 25 & 10 & 0.06 \\
\hline \multirow[t]{2}{*}{ City } & 4 & & & & & & \\
\hline & 509.3 & 17 & 4 & 0.03 & 4 & 1 & $7.85 \times 10-3$ \\
\hline \multirow[t]{2}{*}{ Village } & 8 & & & & & & \\
\hline & 375.3 & 12 & 1 & 0.03 & 1 & 1 & $2.66 \times 10^{-3}$ \\
\hline \multirow[t]{2}{*}{ Farmland } & 9 & & & & & & \\
\hline & 108.6 & 48 & 2 & 0.44 & 0 & 0 & 0 \\
\hline \multirow[t]{2}{*}{ Coniferous forest } & 4 & & & & & & \\
\hline & 314.4 & 70 & 10 & 0.22 & 19 & 3 & 0.06 \\
\hline \multirow[t]{2}{*}{ Tropical rain forest } & 6 & & & & & & \\
\hline & 465.2 & 29 & 3 & 0.06 & 22 & 3 & 0.04 \\
\hline \multirow[t]{2}{*}{ Tropical dry forest } & 9 & & & & & & \\
\hline & 2143. & 438 & 58 & & 71 & 18 & \\
\hline TOTAL & 5 & & & & & & \\
\hline
\end{tabular}




\section{Table 2 (on next page)}

Relative abundances of parrots

Results of generalized linear models showing differences among habitats in the abundance of the two parrot species while controlling for the length (in $\mathrm{km}$ ) of each subtransect. 


\begin{tabular}{lccccc} 
& Estimate & SE & $\mathbf{9 5 \%}$ CI & Wald $\boldsymbol{\mathcal { H }}^{2}$ & P \\
\hline P. chloropterus & & & & & \\
Intercept & -1.951 & 0.46 & {$[-2.85,-1.05]$} & 17.96 & 0.000 \\
City & 3.297 & 0.49 & {$[2.33,4.27]$} & 44.50 & 0.000 \\
Natural & 1.542 & 0.50 & {$[0.57,2.52]$} & 9.63 & 0.002 \\
Rural & 0 &. & $\cdot$ & $\cdot$ &. \\
Subtransect length & .039 & 0.01 & {$[0.03,0.05]$} & 40.28 & 0.000
\end{tabular}

A. ventralis

$\begin{array}{lccccc}\text { Intercept } & -3.625 & 0.53 & {[-4.67,-2.58]} & 45.93 & 0.000 \\ \text { City } & 3.008 & 0.59 & {[1.85,4.17]} & 25.79 & 0.000 \\ \text { Natural } & 2.023 & 0.56 & {[0.92,3.12]} & 12.97 & 0.000 \\ \text { Rural } & 0 & . & . & . & . \\ \text { Subtransect length } & 0.031 & 0.01 & {[0.2,0.05]} & 17.78 & 0.000\end{array}$




\section{Table 3(on next page)}

Differences in relative parrot abundances among habitats.

Estimated marginal means obtained from generalized linear models (see Table 2) for the relative abundance (number of individuals / $\mathrm{km}$ ) of each parrot species in different habitats. 


\begin{tabular}{lcccc}
\cline { 2 - 4 } & \multicolumn{2}{c}{ A.ventralis } & \multicolumn{2}{c}{ P.chloropterus } \\
\cline { 2 - 5 } & mean & $\mathbf{9 5 \%}$ CI & mean & $\mathbf{9 5 \%}$ CI \\
\hline city & 0.096 & $0.056-0.164$ & 0.718 & $0.471-1,096$ \\
natural & 0.036 & $0.024-0.051$ & 0.124 & $0.082-0.187$ \\
rural & 0.004 & $0.001-0.012$ & 0.027 & $0.011-0.064$ \\
& & & & \\
\hline
\end{tabular}




\section{Table 4(on next page)}

Food plants of parrots.

List of plant species and families of which we observed the three species of parrots consuming and dispersing fruits. Asterisks indicate non-native plant species. 


\begin{tabular}{|c|c|c|c|c|c|c|c|}
\hline \multirow[b]{2}{*}{ Plant species } & \multirow[b]{2}{*}{ Family } & \multicolumn{2}{|l|}{ A.ventralis } & \multicolumn{2}{|c|}{ P.chloropterus } & \multicolumn{2}{|l|}{ E.nana } \\
\hline & & Consumed & Dispersed & Consumed & Dispersed & Consumed & Dispersed \\
\hline Simarouba glauca & Simaroubaceae & & & & & Yes & Yes \\
\hline Adonidia merrillii*(Vitchia merrillii & Arecaceae & & & Yes & Yes & & \\
\hline Dypsis (Chrysalidocarpus) lutescens * & Arecaceae & & & Yes & Yes & & \\
\hline Prestoea acuminata & Arecaceae & & & Yes & Yes & & \\
\hline Roystonea (hispaniolana) borinquena & Arecaceae & & & Yes & Yes & & \\
\hline Sabal dominguensis & Arecaeae & Yes & & Yes & Yes & & \\
\hline Coccoloba uvifera & Polygonaceae & & & Yes & Yes & & \\
\hline Inga ruiziana (Gina sp) & Leguminosae & & & Yes & Yes & & \\
\hline Pithecellobium dulce & Leguminosae & Yes & & & & & \\
\hline Tamarindus indica* & Leguminosae & & & Yes & Yes & & \\
\hline Mangifera indica* & Anacardiaceae & Yes & & Yes & Yes & & \\
\hline Sapindus saponaria & Sapindaceae & & & Yes & Yes & & \\
\hline Melicoccus bijugatus & Sapindaceae & & & Yes & & & \\
\hline Terminalia catappa & Combretaceae & & & Yes & Yes & & \\
\hline Sideroxylon foetidissimum & Sapotaceae & Yes & & & & & \\
\hline Azadirachta indica & Meliaceae & Yes & Yes & Yes & & & \\
\hline Casuarina $\mathrm{sp}^{*}$ & Casuarinaceae & Yes & & & & & \\
\hline Araucaria heterophylla* & Araucariaceae & & & Yes & & & \\
\hline Unknown & Unknown & Yes & Yes & & & & \\
\hline
\end{tabular}

2

3

4 


\section{Figure 1}

Parrot species.

Three species of parrots occur in the Dominican Republic: (A) the Hispaniolan amazon (Amazona ventralis), (B) the Hispaniolan parakeet (Psittacara chloropterus), and (C) the Jamaican parakeet (Eupsittula nana). The three species are illegally trapped for sale as pets (D, E and F, respectively). Photo credits: A. Luna $(A, C, F)$ and J.L. Tella (B, D, E).

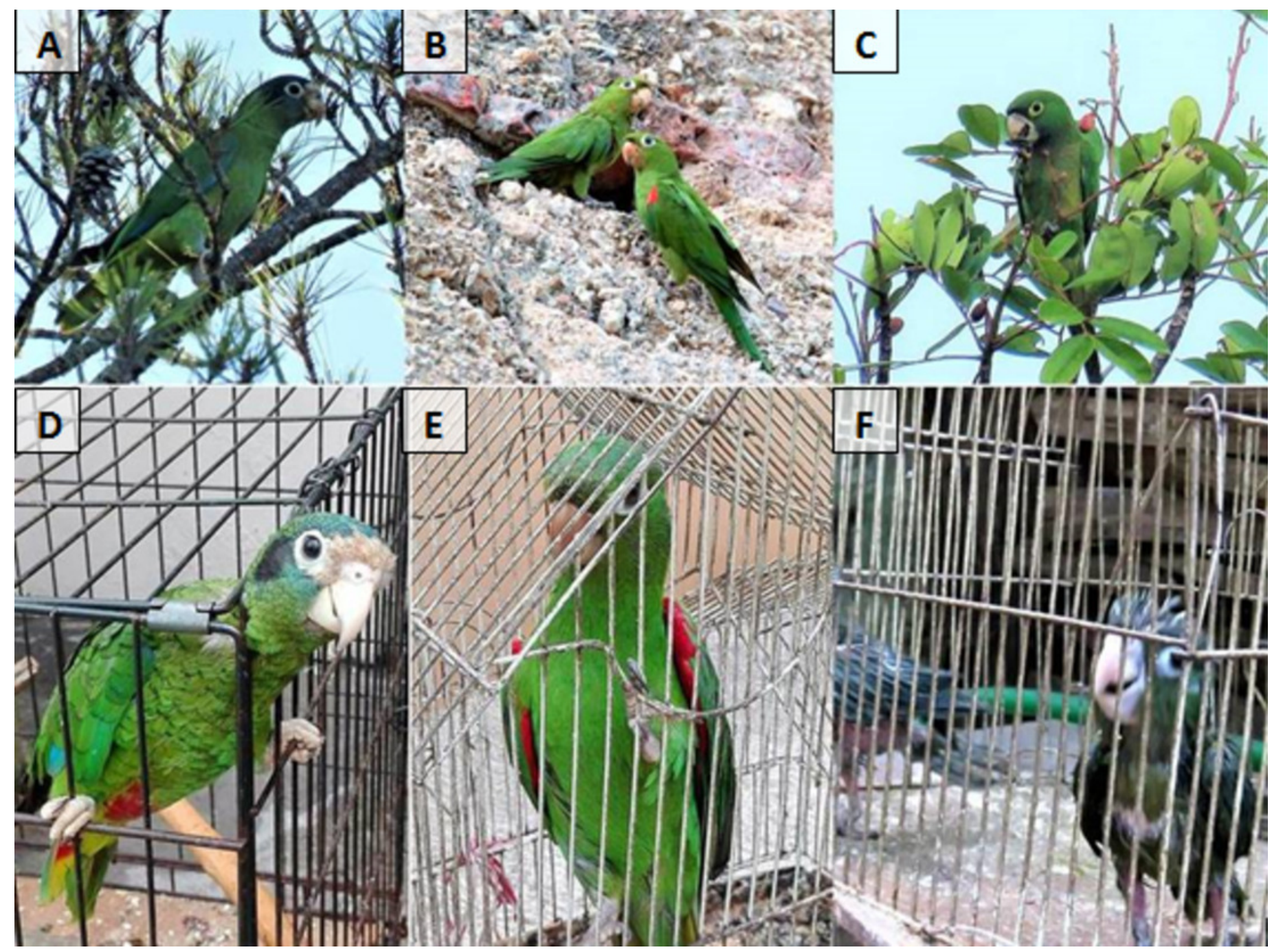




\section{Figure 2}

Location of study area, surveys, and parrot records.

Figure 2. A) Map of the Hispaniolan island including the roadside transects surveyed in Dominican Republic (black lines, totaling $2134.5 \mathrm{kms}$ ), the records of Psittacara chloropterus (white dots), Amazona ventralis (black triangles), both species together (black squares), and Eupsittula nana (asterisks). Numbers 1, 2 and 3 show the location of communal roosts. B) and C) show details for the main cities, Santiago and Santo Domingo, respectively. The main habitats depicted (agriculture, natural and urban areas) were obtained from the Caribbean Land Cover Project (https://lca.usgs.gov/carland/index.php).

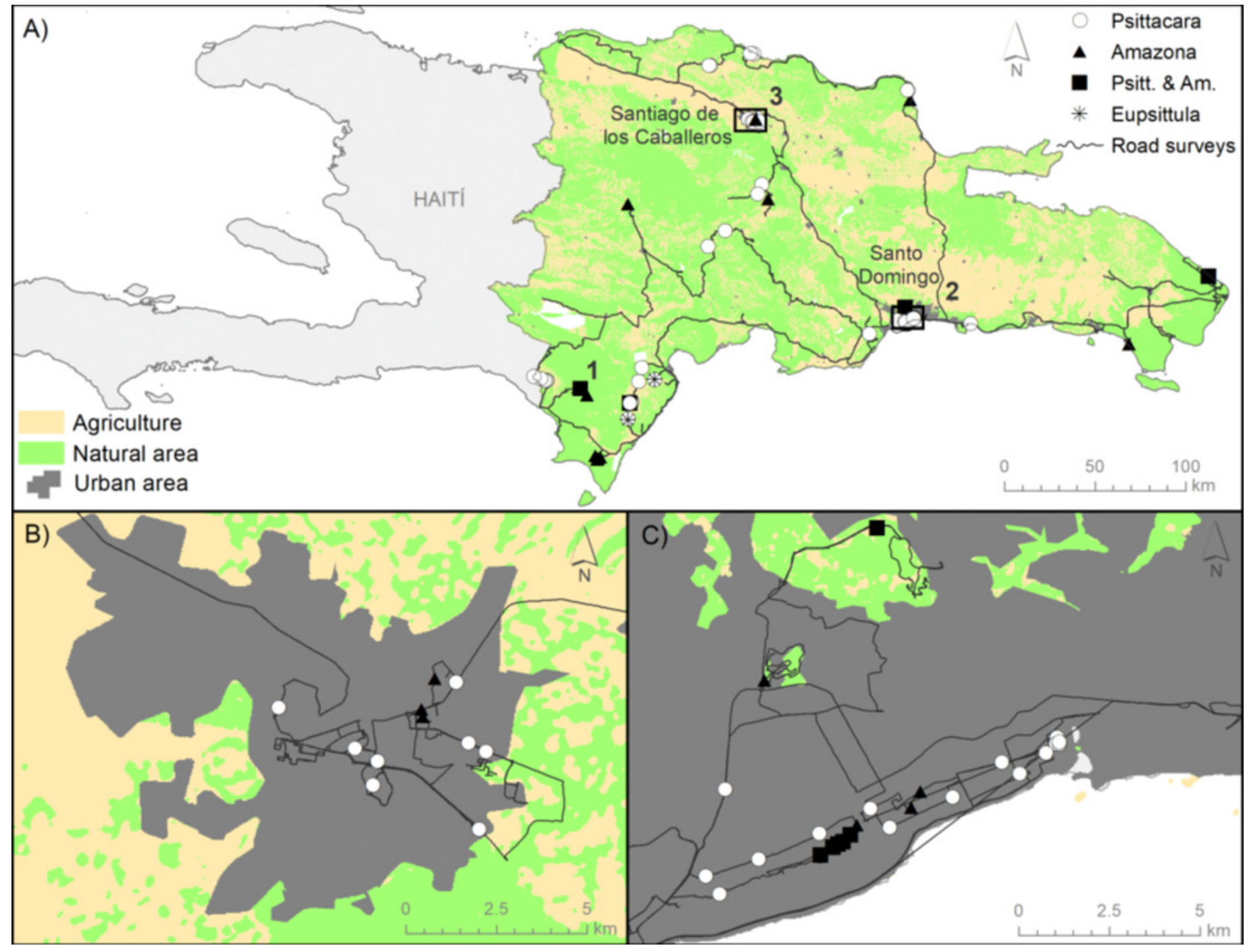




\section{Figure 3}

Seed dispersal

(A) Proportion of seeds dispersed by parrots $(n=306)$ grouped into ten-meter distance intervals. (B) Median dispersal distances for each plant species, with sample sizes indicated to the right of the bars. 


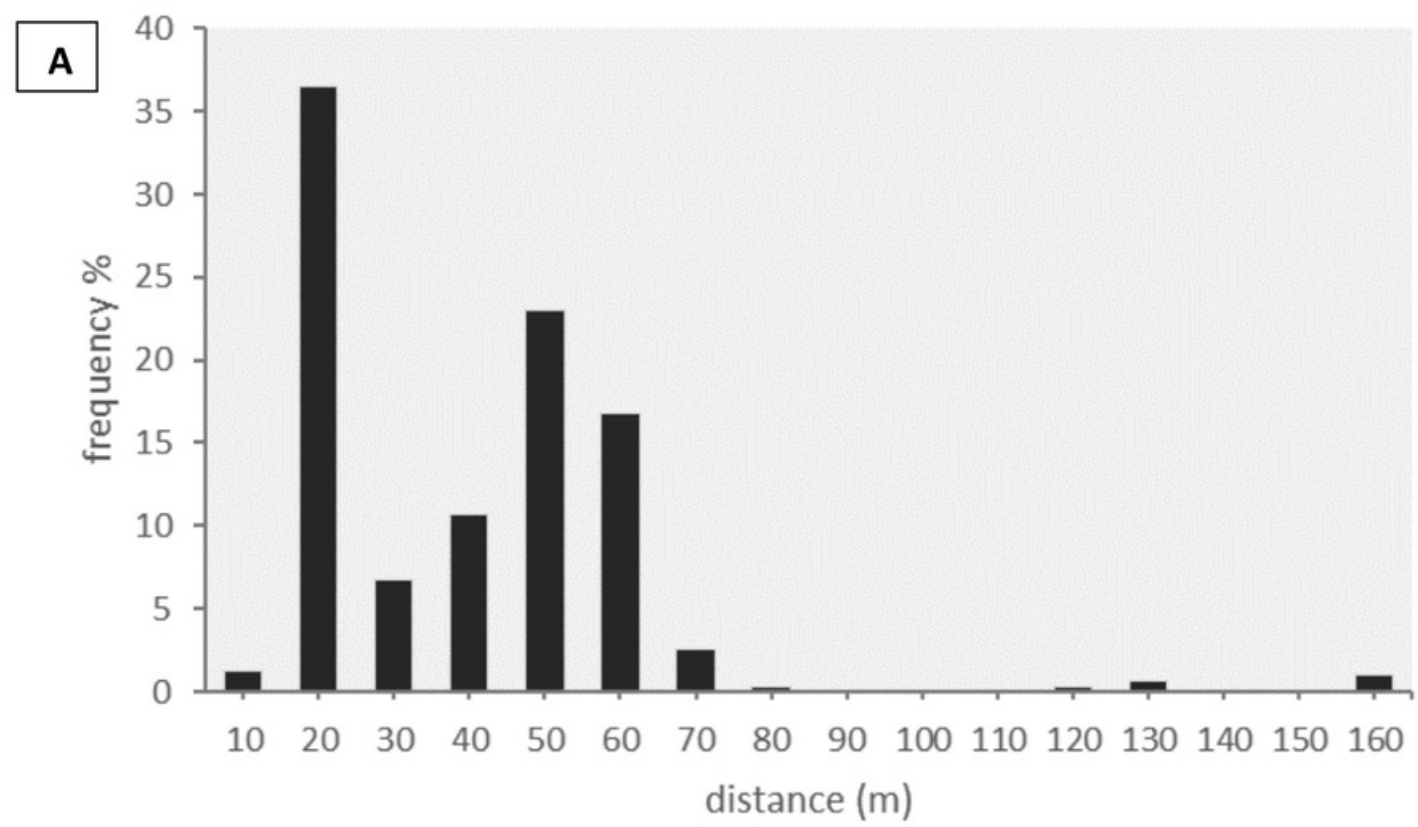

B

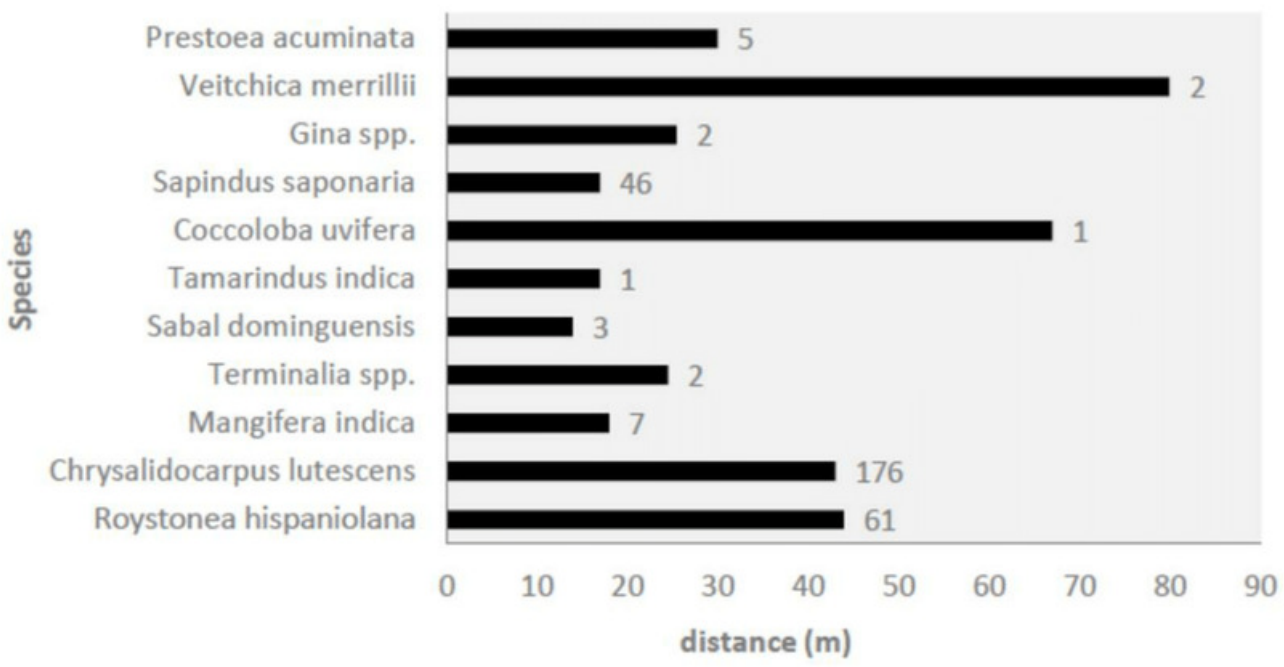

